\title{
The Intraflagellar Transport Machinery
}

\author{
Michael Taschner and Esben Lorentzen \\ Department of Structural Cell Biology, Max-Planck-Institute of Biochemistry, D-82152 Martinsried, Germany \\ Correspondence: taschner@biochem.mpg.de; lorentze@biochem.mpg.de
}

Eukaryotic cilia and flagella are evolutionarily conserved organelles that protrude from the cell surface. The unique location and properties of cilia allow them to function in vital processes such as motility and signaling. Ciliary assembly and maintenance rely on intraflagellar transport (IFT), the bidirectional movement of a multicomponent transport system between the ciliary base and tip. Since its initial discovery more than two decades ago, considerable effort has been invested in dissecting the molecular mechanisms of IFT in a variety of model organisms. Importantly, IFT was shown to be essential for mammalian development, and defects in this process cause a number of human pathologies known as ciliopathies. Here, we review current knowledge of IFT with a particular emphasis on the IFT machinery and specific mechanisms of ciliary cargo recognition and transport.

$T_{\text {he }}^{\text {he }}$ he main structural component of cilia and lagella (interchangeable terms) is an internal microtubule (MT)-based axoneme, which gives the organelle its characteristic elongated shape (Fig. 1). The axoneme is templated from the basal body (BB), a modified centriole anchored to the plasma membrane via transition fibers. In motile cilia, the axonemal MTs are densely decorated with additional multisubunit complexes, such as outer dynein arms (ODAs), inner dynein arms (IDAs), and radial spokes (RS). These motility complexes act together in a highly coordinated fashion to achieve ciliary beating (Lindemann and Lesich 2010). Early studies in the green-alga Chlamydomonas reinhardtii ( $\mathrm{Cr}$ ) and other protozoan species demonstrated that new axonemal subunits are added to the ciliary tip (Rosenbaum and Child 1967; Johnson and Rosenbaum 1992), and the assembly site is thus continuously moving farther away from the site of protein synthesis in the cytoplasm during flagellar growth. Together with the fact that diffusion-limiting protein complexes localize to the transition zone (Reiter et al. 2012), this necessitates an active transport mechanism (i.e., intraflagellar transport [IFT]), to deliver building blocks (e.g., tubulin, ODAs, and IDAs) from the flagellar base to the tip. IFT was first observed in paralyzed C. reinhardtii flagella using differential interference contrast (DIC) microscopy in the early 1990s (Kozminski et al. 1993), and subsequent work has improved the visualization of IFT using a variety of methods not only in the green alga (Engel et al. 2009a), but also in other model systems such as Caenorhabditis elegans (Hao et al. 2009), Tetrahymena thermophila (Jiang et al. 2015), Trypanosoma brucei (Santi-Rocca et al. 2015), and mammalian cells (Williams et al. 2014; Ishikawa and Marshall 2015). In Chlamydomonas, dense particles were seen to move continuously from the base to the tip (anterograde

Editors: Wallace Marshall and Renata Basto

Additional Perspectives on Cilia available at www.cshperspectives.org

Copyright (C) 2016 Cold Spring Harbor Laboratory Press; all rights reserved; doi: 10.1101/cshperspect.a028092

Cite this article as Cold Spring Harb Perspect Biol 2016;8:a028092 

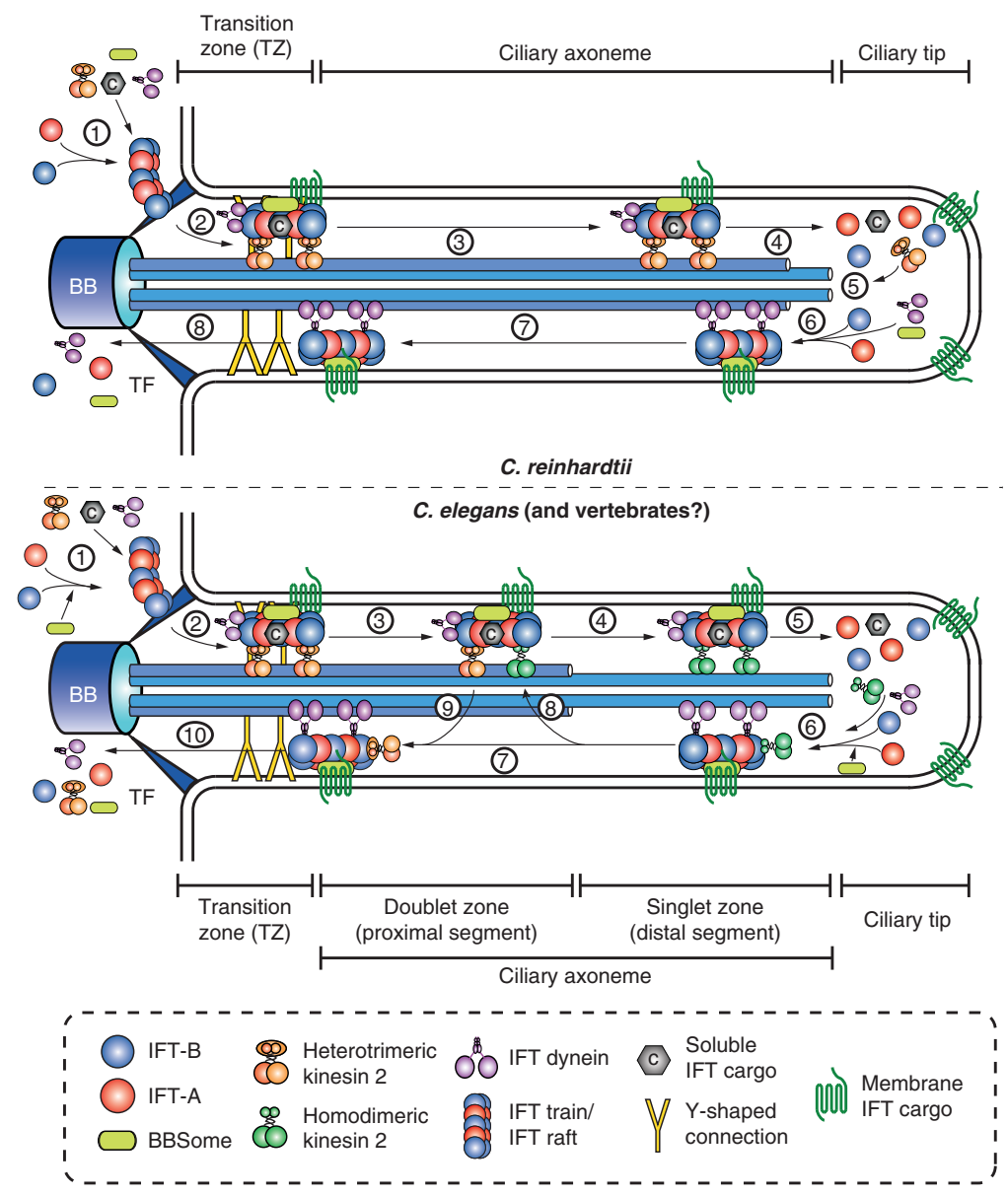

Figure 1. Schematic overview of the main steps during intraflagellar transport (IFT). Because of important differences in various organisms (mainly regarding IFT motors), the individual steps are shown for both Chlamydomonas reinhardtii (top; only one anterograde motor) and Caenorhabditis elegans (bottom; two anterograde motors). (Top) (1) In C. reinhardtii, IFT trains are assembled from IFT-A and IFT-B particles at the ciliary base around the transition fibers and bind to the anterograde motor, the retrograde motor (as a cargo), soluble and membrane cargos, as well as the BBSome. (2) The trains enter the cilium, and (3) move processively toward the ciliary tip (anterograde IFT). (4) At the tip, the IFT trains are remodeled, cargo is unloaded, and the anterograde motor is inactivated (by phosphorylation). (5) The inactive heterotrimeric kinesin 2 motor exits the flagellum independently of retrograde IFT. (6) Retrograde IFT trains assemble at the ciliary tip with active IFT dynein linking them to the ciliary axoneme. (7) Processive retrograde IFT returns the trains and associated proteins back to the ciliary base, and (8) the trains exit flagella and get disassembled. (Bottom) (1) In C. elegans, IFT-A and IFT-B particles also form trains at the ciliary base, and this step is assisted by the BBSome complex. (2) After binding to cargos (retrograde motor, soluble cargos, membrane cargos, BBSome), the heterotrimeric kinesin 2 motor transports the trains through the transition zone (characterized by Y-shaped connectors linking the microtubule (MT) doublets to the ciliary membrane). (3) Along the ciliary proximal segment ("handover zone") heterotrimeric kinesin 2 gradually dissociates from the trains and is replaced by homodimeric kinesin 2 (OSM-3). (4) Along the ciliary distal segment, the trains are exclusively moved by OSM-3. (5) At the tip the trains are remodeled, cargo is unloaded, and the anterograde motor is inactivated. (6) Retrograde trains assemble, which contain activated IFT dynein and inactivated OSM-3 as a retrograde cargo. (7) Retrograde IFT returns the trains back to the ciliary base. (8) Along the proximal segment, OSM-3 is gradually unloaded, and (9) inactive heterotrimeric kinesin 2 is picked up for transport back to the base. (10) Trains exit the cilium and are disassembled. TF, Transition fiber; BB, basal body. 
IFT) at a speed of $\sim 2.5 \mu \mathrm{m} / \mathrm{sec}$ and back from the tip to the base at a faster velocity of $\sim 4 \mu \mathrm{m} /$ sec (retrograde IFT). A follow-up study correlated these particles with large electron-dense structures (IFT trains) forming tight contacts between the outer axonemal MT doublets and the overlying flagellar membrane (Kozminski et al. 1995). An elegant study in the green alga using a combined fluorescence and electron microscopy approach showed that anterograde and retrograde IFT trains run on the B- and A-tubules of the axonemal MT doublets, respectively, explaining why these complexes do not crash into each other inside cilia (Stepanek and Pigino 2016). Efforts to identify and characterize the biochemical components of the IFT machinery (most importantly, molecular motors and IFT complex subunits) made use of several already characterized mutants in various model organisms, such as flagellar assembly ( fla) mutants in C. reinhardtii (Huang et al. 1977; Adams et al. 1982), or chemosensory (che), osmotic avoidance (osm), dye-filling ( $d y f)$, and dauerformation (daf) mutants in C. elegans (Inglis et al. 2007).

Movement of the IFT particles in Chlamydomonas flagella was shown to depend on the FLA10 protein, thus identifying the anterograde IFT motor as heterotrimeric kinesin II (Cole et al. 1993; Walther et al. 1994). IFT trains ceased to move after shifting temperature-sensitive fla10-1 mutant cells to the restrictive temperature; the IFT trains disappeared, and the flagella resorbed owing to a requirement of continuous IFT for Chlamydomonas flagellar maintenance (Kozminski et al. 1995). A more complex situation was observed in C. elegans, where heterotrimeric kinesin II mutants are still able to assemble neuronal sensory cilia because of the presence of homodimeric kinesin II (OSM-3) as a second anterograde IFT motor. These two motor complexes function redundantly to build the ciliary middle segment containing axonemal MT doublets, but OSM-3 functions alone to build the distal singlet zone (Snow et al. 2004). A recent study investigated the relationship between the two anterograde motors in more detail and showed that rather than transporting IFT trains together as previously sug- gested, the two different kinesin motors localize to different regions of the cilium (heterotrimeric kinesin II more proximal, OSM-3 more distal) (Prevo et al. 2015). Despite the presence of an OSM3 homolog in vertebrates (Kif17), heterotrimeric kinesin II is the main motor complex for ciliary assembly in mice (Nonaka et al. 1998; Marszalek et al. 1999) and zebrafish (Zhao et al. 2012), but Kif17 is required for the proper formation of specific subtypes of the organelle (Insinna et al. 2009; Zhao et al. 2012).

Cytoplasmic dynein 2 was identified as the retrograde IFT motor that carries the IFT-complex (and cargos/turnover products) back from the ciliary tip. Inactivation of subunits in this complex leads to short cilia with bulges accumulating IFT proteins in a variety of model systems (Pazour et al. 1998; Porter et al. 1999; Signor et al. 1999; Perrone et al. 2003; Hou et al. 2004; May et al. 2005). The process of IFT can be subdivided into several distinct phases (see Fig. 1). IFT particles and trains are first assembled at the ciliary base, where they also bind to ciliary cargos followed by processive anterograde transport to the ciliary tip. At the tip, the ciliary cargos are unloaded, and the IFT particles are remodeled and switched to a retrograde mode by inactivating the anterograde and activating the retrograde motor. Finally, IFT particles move back to the base, where they are recycled for subsequent rounds of transport. Although a general outline of the IFT cycle is in place, the molecular mechanisms of most steps of this process remain poorly understood.

\section{THE DISCOVERY OF THE IFT COMPLEX}

The key to biochemical purification and characterization of endogenous IFT complexes from C. reinhardtii was the temperature-sensitive kinesin II mutant ( fla10-1), in which the activity of the anterograde heterotrimeric kinesin II motor could be abrogated by a shift to the nonpermissive temperature. Two independent studies used this strain to identify a large protein complex, which was only present in the flagella at the permissive temperature (Piperno and Mead 1997; Cole et al. 1998). Although Piperno and Mead (1997) identified 13 proteins as 
members of this complex, Cole et al. (1998) reported 15 proteins and showed that the complex dissociated at increased ionic strength into two biochemically distinct subcomplexes, IFT$\mathrm{A}$ and IFT-B. The components of the IFT complex in C. reinhardtii were named according to their apparent molecular weight, as judged by their migration in sodium dodecyl sulfate polyacrylamide gel electrophoresis(SDS-PAGE). In the rest of this paper, we will use this Chlamyomonas nomenclature for the proteins even when referring to work carried out in other systems in which the factors have different names (Table 1). Immunofluorescence and immunogold electron microscopy showed that these proteins were highly enriched at the flagellar base but were also detectable as punctuate stainings along the ciliary axoneme (for examples, see Deane et al. 2001; Pedersen et al. 2005; Hou et al. 2007; Fan et al. 2010). This subcellular distribution is also characteristic of IFT proteins in other model systems (for example, see Blacque and Leroux 2006; Tsao and Gorovsky 2008a; Follit et al. 2009; Huet et al. 2014).

Additional IFT proteins have since then been identified (Piperno et al. 1998; Wang et al. 2009; Fan et al. 2010; Ishikawa et al. 2014), and, currently, six proteins are believed to form the IFT-A subcomplex (IFT144, 140, 139, 122, 121, and 43), whereas 16 subunits are found in IFT-B (IFT172, 88, 81, 80, 74, 70, 57, 56, 54, 52, 46, $38,27,25,22$, and 20). Analysis of mutants deficient for those factors showed that IFT-A mutants typically yielded ciliary defects similar to cytoplasmic dynein 2 mutants (stumpy organelles filled with IFT material) (for example, see Piperno et al. 1998; Blacque et al. 2006; Tran et al. 2008; Iomini et al. 2009), whereas IFT-B mutants usually had severe ciliogenesis defects (examples in Pazour et al. 2000; Tsao and Gorovsky 2008a;

Table 1. Nomenclature of IFT proteins in several model organisms

\begin{tabular}{|c|c|c|c|c|c|c|}
\hline \multirow[b]{2}{*}{ Complex } & \multirow[b]{2}{*}{ General } & \multicolumn{5}{|c|}{ Alternative name in other organisms (if different) } \\
\hline & & $\begin{array}{c}\text { Chlamydomonas } \\
\text { reinhardtii }\end{array}$ & $\begin{array}{c}\text { Trypanosoma } \\
\text { brucei }\end{array}$ & $\begin{array}{c}\text { Caenorhabditis } \\
\text { elegans }\end{array}$ & $\begin{array}{c}\text { Danio } \\
\text { rerio }\end{array}$ & Mammals \\
\hline \multicolumn{7}{|l|}{ IFT-B } \\
\hline \multirow[t]{10}{*}{ IFT-B1 } & IFT88 & - & - & OSM-5 & Polaris & Polaris/Tg737 \\
\hline & IFT81 & - & - & - & - & - \\
\hline & IFT74 & - & - & - & - & - \\
\hline & IFT70 & FAP259 & PIFTB2 & DYF-1 & Fleer & TTC30A/B \\
\hline & IFT56 & DYF-13 & PIFTC3 & DYF-13 & - & TTC26 \\
\hline & IFT52 & BLD1 & - & OSM-5 & - & NGD5 \\
\hline & IFT46 & - & - & DYF-6 & - & - \\
\hline & IFT27 & - & - & (Absent) & - & RabL4 \\
\hline & IFT25 & FAP232 & - & (Absent) & - & HSPB11 \\
\hline & IFT22 & FAP9 & - & IFTA-2 & - & RabL5 \\
\hline \multirow[t]{6}{*}{ IFT-B2 } & IFT172 & - & - & OSM-1 & - & SLB \\
\hline & IFT80 & - & - & CHE-2 & - & WDR56 \\
\hline & IFT57 & - & - & CHE-13 & - & Hippi \\
\hline & IFT54 & FAP116 & - & DYF-11 & Elipsa & Traf3IP1/MIP-T3 \\
\hline & IFT38 & FAP22 & PIFTA1 & DYF-3 & Qilin & Cluap1 \\
\hline & IFT20 & - & - & - & - & - \\
\hline \multicolumn{7}{|l|}{ IFT-A } \\
\hline \multirow[t]{3}{*}{ Core } & IFT144 & - & - & DYF-2 & - & WDR19 \\
\hline & IFT140 & - & - & CHE-11 & - & WDTC2 \\
\hline & IFT122 & FAP80 & - & DAF-10 & - & WDR10 \\
\hline \multirow[t]{3}{*}{ Noncore } & IFT139 & - & - & - & - & THM1/TTC21B \\
\hline & IFT121 & - & PIFTD4 & IFTA-1 & - & WDR35 \\
\hline & IFT43 & - & - & - & - & C14ORF179 \\
\hline
\end{tabular}


Adhiambo et al. 2009), comparable to kinesin II mutants (with a few important exceptions, see below). These results showed that IFT-A and IFT-B were not only biochemically distinct complexes, but suggested that they also have separate functions in retrograde and anterograde transport of cargos, respectively. Although this simplistic view may be true to a large extent, several exceptions have since been reported, such as the importance of the IFT-A factors for ciliary protein import (Mukhopadhyay et al. 2010) or the requirement for IFT-B proteins in ciliary cargo export (Keady et al. 2012; Eguether et al. 2014; Huet et al. 2014). Importantly, IFT mutations in mammals were shown to cause severe pathologies (ciliopathies) (for review, see Fliegauf et al. 2007) and affect cellular signaling pathways (Huangfu et al. 2003; Wang et al. 2006). These discoveries highlighted the importance of IFT in particular (and cilia in general) in human development, tissue homeostasis, and disease, and led to an increased interest in understanding cilium formation and function.

Bioinformatic analysis of IFT proteins revealed well-known protein-protein interaction motifs (Taschner et al. 2012), such as tetratricopeptide repeats (TPRs), WD-40 repeats, and coiled coils, consistent with their assembly into a large macromolecular complex and their putative binding to hundreds of ciliary proteins found in ciliary and flagellar proteomes (Ostrowski et al. 2002; Pazour et al. 2005; Liu et al. 2007). Nevertheless, assays to identify direct interactions involving IFT proteins using bacterial coexpressions/pulldowns and yeast two-hybrid analyses only gave limited insights. Recently, the recombinant reconstitution and biochemical characterization of IFT subcomplexes (primarily from C. reinhardtii) has improved our understanding especially of the IFT-B complex, and has led to a first glimpse on high-resolution structures of IFT proteins.

\section{THE ARCHITECTURE OF THE IFT-B COMPLEX}

The IFT-B Core (IFT-B1)

Some of the first insights into the organization of the 16-subunit IFT-B complex was obtained when Lucker et al. (2005) showed that in Chla- mydomonas, several subunits formed a salt-stable subcomplex (called IFT-B core), and others (peripheral subunits) dissociated at an $\mathrm{NaCl}$ concentration of $300 \mathrm{~mm}$. The originally identified IFT-B core contained six proteins (IFT88, $81,74,52,46$, and 27 ), but four additional members in the green alga were identified in subsequent studies, namely, IFT70 (Fan et al. 2010), IFT25 (Lechtreck et al. 2009b; Wang et al. 2009), IFT22 (Wang et al. 2009), and IFT56 (Ishikawa et al.2014). Homologs of these factors have been identified in many other model systems, with the exceptions being C. elegans, which lacks IFT27 and IFT25, and Drosophila, which lacks IFT81, 74, 27, 25, and 22 (Cole and Snell 2009). Although most IFT-B core factors are obligatory for ciliogenesis, some factors have more specialized roles in cilium formation and function (see below).

Interaction studies of IFT-B core proteins using yeast two-hybrid analysis or bacterial coexpressions/pulldowns suggested direct interactions between IFT27 and IFT25 (Follit et al. 2009; Wang et al. 2009; Bhogaraju et al. 2011), IFT70 and IFT52 (Zhao and Malicki 2011; Howard et al. 2013), IFT70 and IFT46 (Fan et al. 2010), IFT81 and IFT74 (Lucker et al. 2005; Kobayashi et al. 2007), IFT88, IFT52, and IFT46 (Lucker et al. 2010), and, finally, IFT56 and IFT46 (Swiderski et al. 2014). These initial insights into subunit interactions paved the way for the recombinant reconstitution of several IFT-B core subcomplexes using Chlamydomonas proteins (Taschner et al. 2011) as well as a nine-subunit IFT-B core lacking only IFT56 (Taschner et al. 2014). In addition, most of the direct protein-protein interactions were mapped to individual domains in IFT proteins (Taschner et al. 2011, 2014), leading to an initial interaction map of the nine-subunit IFT-B core with domain resolution (Fig. 2). Several of these interactions appear to occur through composite interfaction interfaces because they require the presence of more than two proteins, providing an explanation for why they were not observed in yeast two-hybrid assays. IFT81, 74, 52, and 46, for example, only bind when preassembled IFT81/74 and IFT52/46 complexes are used. Similarly, IFT22 interacts with a minimal 
IFT81/74 complex, but not with the individual IFT81 or IFT74 fragments (Taschner et al. 2014). Salt-stability tests of the nonameric IFT-B core complex confirmed previously published results (Lucker et al. 2005), but showed that this complex was stable at $\mathrm{NaCl}$ concentrations $>2 \mathrm{M}$ in vitro, suggesting substantial hydrophobic interactions between subunits (Taschner et al. 2014). This idea was confirmed by several crystal structures of IFT-B core subcomplexes. The first IFT subcomplex structure obtained was that of Chlamydomonas IFT27/25 (Bhogaraju et al. 2011), in which the atypical small GTPase IFT27 binds to IFT25 via an unusually long carboxy-terminal helix through hydrophobic contacts. This hydrophobicity is the likely explanation for why IFT27 can only be made recombinantly in the presence of IFT25 (Bhogaraju et al. 2011) and for the instability of endogenous IFT27 in mouse cells lacking IFT25 (Keady et al. 2012). Interestingly, the ciliate T. thermophila ( $T t$ ) does not have an IFT25 homolog, but does have an IFT27 protein that lacks the hydrophobic residues. TtIFT27, unlike the algal and mouse proteins, can be produced recombinantly in a soluble form (M Taschner and E Lorentzen, unpubl.).

The high-resolution structure of the IFT70/ 52 complex is also in agreement with the high salt stability of the IFT-B core complex. The tetratricopeptide repeat (TPR)-containing superhelical protein IFT70 was shown to wrap tightly in two full turns around a short (40 residues) and largely unstructured, proline-rich peptide of IFT52 that can be considered part of the hydrophobic core required for proper folding of the IFT70 protein (Taschner et al. 2014). Finally, a complex between the carboxyterminal domains of TtIFT52 and TtIFT46 also revealed the presence a large hydrophobic surface between the two proteins (Taschner et al. 2014), and that this carboxy-terminal region of IFT46 is necessary for proper folding of the IFT52 carboxy-terminal domain.

\section{The Peripheral IFT-B Complex (IFT-B2)}

Several peripheral subunits (IFT172, 80, 57, and 20) were reported to be loosely associated with the IFT-B core complex (Lucker et al. 2005), and the two additional peripheral factors IFT54 (Kunitomo and Iino 2008; Omori et al. 2008; Berbari et al. 2011) and IFT38 (Ou et al. 2005b; Inglis et al. 2007; Pasek et al. 2012) were identified later. With respect to protein-protein interactions, IFT20 was shown to bind to the carboxy-terminal coiled-coil region of IFT54 in pulldowns (Omori et al. 2008; Follit et al. 2009) and to IFT57 in yeast-two-hybrid assays (Baker et al. 2003), suggesting the formation of a ternary complex between these three subunits. We could recently confirm the presence of a stable IFT54/ 20 complex of Chlamydomonas, but found that IFT57 binds strongly to IFT38 and only weakly to IFT20 (Taschner et al. 2016). The IFT57/38 and IFT54/20 complexes interact with each other to form a heterotetramer, although this interaction appears to be much weaker than the interactions holding together the IFT54/20 and IFT57/38 heterodimers (Taschner et al. 2016).

Surprisingly, we found that the six peripheral IFT-B subunits form a stable complex in the absence of the IFT-B1 complex and show that IFT57/38 is a central component that directly interacts with IFT172, IFT80, and IFT54/20 (Taschner et al. 2016). These results show that the IFT-B complex is composed of two distinct subcomplexes that we refer to as IFT-B1 (the IFT-B core) and IFT-B2 (for the complex containing the proteins formerly referred to as peripheral IFT-B proteins) (Fig. 2). This conclusion, based on the analysis of purified Chlamydomonas proteins, was recently confirmed using a "visible immunoprecipitation" (VIP) approach with human proteins (Katoh et al. 2016), as well as in human cells in a large-scale proteomic study (Boldt et al. 2016). With regard to salt stability, it should be noted that five of the six IFT-B2 proteins are stable at $\mathrm{NaCl}$ concentrations of $1 \mathrm{~m}$ (Taschner et al. 2016), with IFT172 being the only weakly attached subunit, confirming previously published data (Cole et al. 1998; Pedersen et al. 2005).

The presence of two stable subcomplexes within IFT-B raised the question about how they interact with each other to form the full IFT-B complex. Mixing of IFT-B1 and IFT-B2 led to the reconstitution of a nearly complete 15-subunit IFT-B complex (missing only 
The Intraflagellar Transport Machinery

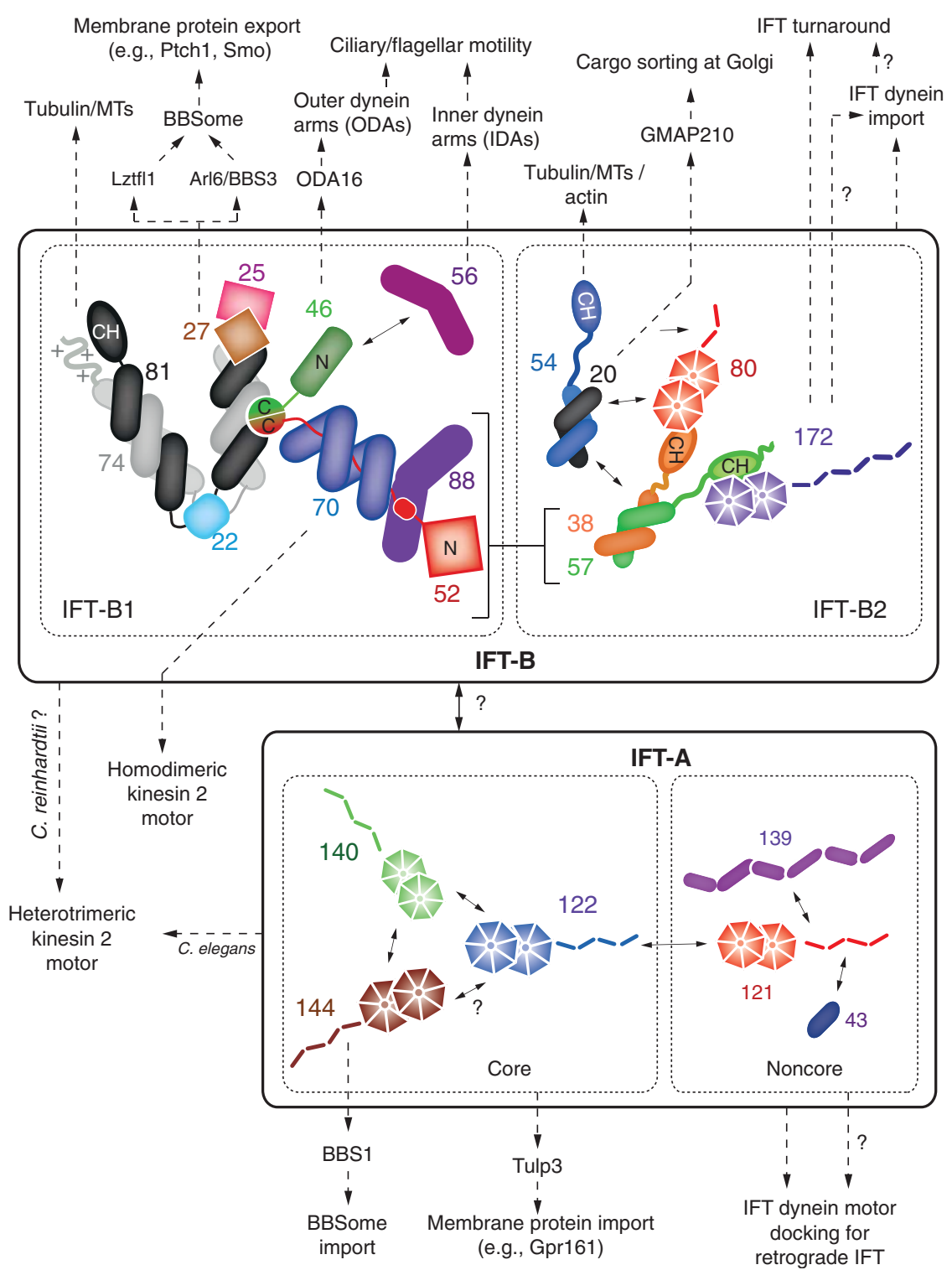

Figure 2. Interactions within intraflagellar transport (IFT) proteins and interaction between IFT proteins/ complexes and ciliary motor/cargo proteins (see text for details). MT, Microtubule; C. reinhardtii, Chlamydomonas reinhardtii; C. elegans, Caenorhabditis elegans.

IFT56), and pulldown analyses between recombinant parts showed that the minimal requirement for this binding is a preformed IFT88/52N subcomplex (on the IFT-B1 side) that directly contacts the IFT57/38 subcomplex in IFT-B2 (Fig. 2) (Taschner et al. 2016). The necessity for the presence of four distinct proteins explains why such an interaction was previously missed in yeast-two-hybrid analysis and similar experiments. Although our understanding of IFT-B complex architecture has significantly improved in recent years, the relative position of proteins and ciliary cargo-binding sites within the IFT complex are still unknown. Further studies using not only X-ray crystallography but also single-particle cryo-EM will be necessary to 
gain further insights into the ciliary assembly machinery.

\section{FUNCTIONS OF IFT-B PROTEINS IN IFT-B COMPLEX FORMATION AND STABILITY}

The specific functions of individual IFT-B proteins in ciliogenesis are still largely enigmatic. The reason for this is that null mutants of most IFT-B factors typically result in IFT complex destabilization and thus a strong ciliogenesis defect, masking the specific contribution of the missing protein to IFT regulation and/or cargo transport. IFT52, for example, is indispensable for IFT-B complex formation because of its central location within the complex and interaction with at least five other IFT-B subunits (Fig. 2). Consistently, the ift52/bld $1 \mathrm{mu}$ tant in Chlamydomonas is unable to assemble flagella and shows strong destabilization of several IFT-B1 subunits (Richey and Qin 2012), with the exception of the IFT27/25 subcomplex, which forms independently of IFT-B1, and IFT46 (Brazelton et al. 2001). Short and malformed flagella are formed in the ift46 mutant, in which not only the IFT-B1 protein IFT81, but also the IFT-B2 proteins IFT57 and IFT20 were destabilized, indicating an interdependence of the IFT-B1 and B2 subcomplexes for stability (Hou et al. 2007). Interestingly, the cellular levels of the weakly attached IFT-B2 protein IFT172 were not substantially affected, but a strong increase was observed for IFT-A proteins. Quantification of transcript levels showed an upregulation of mRNAs for all of the examined IFT-factors, which led to the model that ift46 cells try to compensate for the loss of the IFT-B1 complex by upregulating expression of IFT genes. This upregulation leads to an increase in the abundance of IFT proteins that are not dependent on the presence of an intact IFT-B complex for stability (such as IFT-A components). However, IFT proteins whose stability depends on IFT46 are likely degraded in the absence of IFT46 and thus less abundant despite the up-regulated mRNA levels (Hou et al. 2007). Interestingly, the authors also identified an ift46 suppressor mutant in which the carboxy-terminal IFT46 region was expressed, and found that in these cells the levels of IFT-B proteins were stabilized, which is in agreement with the fact that this domain is required for IFT-B1 complex stability (Fig. 2) (Lucker et al. 2010; Taschner et al. 2011, 2014). Intriguingly, the higher levels of IFT-A proteins did not return to wild-type levels in this strain for unknown reasons (Hou et al. 2007). A similar destabilization of IFT-B1 (IFT81 and IFT46) and IFT-B2 (IFT57 and IFT20) proteins as well as a slight increase in an IFT-A protein (IFT139) were recently observed in an IFT74 (ift74-2) Chlamydomonas mutant (Brown et al. 2015). IFT88 is not required for the stability of the IFT-B1 complex (Pazour et al. 2000; Richey and Qin 2012; Taschner et al. 2014), but as indicated above is part of the interface between IFT-B1 and IFT-B2 (Boldt et al. 2016; Taschner et al. 2016). Consistently, the IFT-B complex formed in the ift 88 mutant is smaller (Richey and Qin 2012), and IFT57 (IFTB2 component) but not IFT81 (IFT-B1 component) is destabilized (Pazour et al. 2000). Again, the abundance of an IFT-A protein was increased (Pazour et al. 2000). Finally, knockdown of IFT70 in Chlamydomonas also led to a destabilization of IFT-B1 and an increase in IFT-A proteins (Fan et al. 2010).

Taken together, the observed destabilization of several factors within the IFT-B complex in the absence of a particular protein creates a serious problem for the dissection of the individual functions of a particular IFT component, and more subtle alterations compatible with IFT complex assembly (e.g., deletions of IFT protein domains dispensable for complex formation) will be necessary to obtain a detailed understanding of the contribution of individual factors to IFT.

\section{FUNCTIONS OF IFT-B PROTEINS IN CARGO TRANSPORT, IFT REGULATION, AND SIGNALING}

IFT46 and IFT56 Function in the Transport of Motility Factors

Despite the difficulties listed above, some examples of specific cargo transport functions of IFT proteins are available in the literature, and these discoveries were possible because the mutants 
were-at least to some extent-able to form cilia and flagella for further analyses. For instance, IFT46 has been linked to the specific transport of outer dynein arms (ODAs) into Chlamydomonas flagella. ODAs were previously shown to depend on IFT for axonemal assembly (Piperno et al. 1996) and to interact with the IFT complex (Qin et al. 2004). The short axonemes of ift46 mutant flagella lacked ODAs; and, in a suppressor strain (expressing the carboxy-terminal IFT46 domain), overall flagellar assembly, but not axonemal ODA deficiency, was rescued (Hou et al. 2007). This implies a function of the IFT46 amino-terminal domain, which is not required for IFT-B1 complex stability (Taschner et al. 2014), in the transport of ODAs as cargos. In agreement with this notion, a direct interaction between IFT46 and the ODA assembly factor ODA16 was detected both by yeast-two-hybrid analysis as well as by pulldowns using recombinantly expressed proteins (Ahmed et al. 2008), but further examination of amino-terminal and carboxy-terminal IFT46 domains was not published. IFT46 knockdown in zebrafish was recently shown to lead to a similar shortening of cilia in various organs and to several phenotypes indicative of motility defects (e.g., left-right asymmetry defects), but analysis of the axonemal ultrastructure did not show an obvious ODA assembly defect (Lee et al. 2015).

In contrast to the ODA assembly defect in ift46 mutants, the flagella in this mutant had no obvious deficiency in inner dynein arms (IDAs) (Hou et al. 2007). Transport of these motor complexes was shown to specifically require IFT56/TTC26 (Ishikawa et al. 2014). ift56 mutant cells have normal levels of IFT and can assemble flagella of nearly wild-type length but display motility defects, and proteomic analysis of isolated ift56 flagella showed a deficiency in certain types of IDAs (in addition to other motility-related components). A direct interaction between IDAs and IFT56 was not reported, but the authors speculate that IFT56 might bind IDAs via an IDA chaperone (TWI1) (Ishikawa et al.2014). IDA deficiencies and ciliary motility defects were also observed in a mouse mutant (hop mouse) of IFT56 (Bryan 1983), and knockdown of the zebrafish homolog similarly led to shorter cilia with abnormal motility (Ishikawa et al. 2014). Additional phenotypes in the hop mouse could not be explained by defects in motile cilia, and a recent study showed that nonmotile primary cilia in these mice have a specific defect in Hedgehog ( $\mathrm{Hh}$ ) signaling (Swiderski et al. 2014).

\section{IFT27 and IFT25 Function in BBSome Transport and Regulate Hedgehog (Hh) Signaling}

Another IFT-B protein with a specific function in Hh signaling is the atypical small GTPase IFT27 (Keady et al. 2012; Eguether et al. 2014). It was first reported that the IFT25 knockout mouse, unlike most other IFT-B mutant mice, neither had a detectable defect in ciliogenesis, nor did cilia on those cells have any obvious structural abnormalities (Keady et al. 2012). However, several phenotypes hinted toward defective Hh signaling, which requires coordinated ciliary import and export of signaling factors such as the membrane proteins Patched1 (Ptch1) and Smoothened (Smo), depending on the absence or presence of $\mathrm{Hh} \mathrm{li-}$ gand. Both Ptch1 and Smo accumulated in the cilia of ift $25^{-/-}$MEFs, hinting at a role for IFT25 in the ciliary export of these proteins. However, IFT27 was destabilized in mutant cells, and so the defect could not be attributed specifically to the loss of IFT25 (Keady et al. 2012). A subsequent study showed that the IFT27 knockout mouse, despite having wildtype levels of IFT25, also had a similar export defect of Ptch1 and Smo (Eguether et al. 2014). Furthermore, the mutant cilia accumulated the multisubunit BBSome complex (Eguether et al. 2014; Mick et al. 2015), a well-known adapter for the transport of ciliary membrane proteins (Loktev et al. 2008; Jin et al. 2010). The authors explained their findings by a defective link between the IFT complex (IFT27) and the BBSome via the intermediate protein Lztfl1 (Seo et al. 2011), which leads to the accumulation of the BBSome and its membrane cargos (Ptch1 and Smo) in mutant cilia (Eguether et al. 2014). A similar requirement for IFT27 in 
BBSome removal from cilia was reported in a separate study, but the authors attributed this to a function of the protein in the stabilization of the small GTPase Arl6/BBS3 required for assembly of the BBSome membrane coat inside cilia (Liew et al. 2014). GTP-bound Arl6/ $\mathrm{BBS} 3$ recruits the BBSome components (via interaction with BBS1) to membranes to initiate the formation of a planar membrane coat (Jin et al. 2010; Mourão et al. 2014). After Arl6 GTP hydrolysis at the ciliary tip, the transient stabilization of the nucleotide-free form of Arl6 through binding to IFT27 was proposed to be essential for the formation of a BBSome coat and efficient retrograde movement and ciliary export (Liew et al. 2014). Mutations in IFT27 have been found in patients with Bardet-Biedl syndrome (BBS), strengthening the functional link between this GTPase and the BBSome (Aldahmesh et al. 2014).

The functions of the IFT27/25 complex in unicellular eukaryotes have not been investigated in similar detail, but the presence of a BBSome in Chlamydomonas and other singlecelled organisms implies that a similar mechanism could be at work there for export of membrane cargos. IFT27 in T. brucei was reported to participate in retrograde IFT via import of the IFT-A complex and the retrograde dynein motor (Huet et al. 2014). This was not observed in mammalian cells and may represent a speciesspecific effect in Trypanosoma.

\section{IFT172 Functions in IFT Turnaround at the Ciliary Tip}

IFT172 is mutated in a temperature-sensitive mutant strain of C. reinhardtii $\left(\right.$ fla $11^{\text {ts }}$ ) (Pedersen et al. 2005). These cells have normal levels of anterograde and retrograde IFT at the permissive temperature (Iomini et al. 2001), but accumulate IFT proteins near the flagellar tip after a shift to restrictive conditions (Iomini et al. 2001; Pedersen et al. 2005, 2006) This suggests that, in the absence of functional IFT172, the transition from anterograde to retrograde IFT is compromised. The MT plus-end binding protein EB1 localizes to the flagellar tip in Chlamydomonas (Pedersen et al. 2003), interacts with IFT172 in coimmunoprecipitation experiments (Pedersen et al. 2005), and the flagellar localization of EB1 is abolished in the fla $11^{\text {ts }}$ strain at the restrictive temperature (Pedersen et al. 2003). Although these results would suggest a requirement for IFT172 in the anterograde transport of EB1, flagellar tip localization of EB1 does not depend on IFT (Pedersen et al. 2003) and has recently been shown to occur by a diffusion and capture mechanism (Harris et al. 2016). The underlying molecular mechanism by which IFT172 promotes IFT turnaround at the tip and the potential role for EB1 in this process remain elusive.

A function of IFT172 in the switch between anterograde and retrograde transport was also implied in a study using the ciliate T. thermophila where recombination can be used to create specific gene knockouts (Dave et al. 2009). Deletion of IFT172 abolished ciliogenesis, showing that this factor is essential for anterograde IFT (Tsao and Gorovsky 2008a). Wild-type cilia could be restored by rescue with full-length IFT172, but several IFT proteins accumulated at the ciliary tip when a part of the carboxyl terminus was missing (interestingly the same region that contains the Chlamydomonas fla $11^{\text {ts }}$ mutation). The authors speculated that the carboxy-terminal region of the protein interacts with EB1 at the tip, and that such an interaction is required for efficient regulation of IFT turnaround (Tsao and Gorovsky 2008a).

IFT20 Is a Golgi-Associated Protein Involved in Membrane Protein Sorting to the Cilium

Unlike other IFT proteins, IFT20 not only localizes to the cilium but also to the Golgi complex in mammalian cells (Follit et al. 2006, 2008), where it is directly tethered to the Golgi protein GMAP210/Trip11 (Follit et al. 2008). Both IFT2 0 and GMAP210 are essential for embryonic development (Follit et al. 2008; Jonassen et al. 2008), and it was proposed that they act together in the sorting of membrane cargos destined for the cilium. Indeed, reduced levels of certain ciliary membrane proteins were observed after moderate knockdown of IFT20 (Follit et al. 2006) and in the cilia of embryonic kidney cells 
from GMAP210 knockout mice (Follit et al. 2008). Whether IFT20 also functions in Golgi to cilium transport in unicellular organisms such as Chlamydomonas remains to be shown.

\section{IFT81/74 and IFT54 Bind $\alpha \beta$-Tubulin}

\section{Dimers and MT}

The most abundant IFT cargo is the $\alpha \beta$-tubulin heterodimer, the main component of the MTs of the ciliary axoneme. About 350,000 tubulin dimers are required to construct a full-length flagellum in Chlamydomonas (Bhogaraju et al. 2014), and this process takes $\sim 90 \mathrm{~min}$ to be complete (Rosenbaum et al. 1969). Tubulin was shown to move along the axoneme with IFT particles in C. reinhardtii (Craft et al. 2015) and C. elegans (Hao et al. 2011), and a first insight into how it is recognized as a cargo came from studies on the amino-terminal domains of IFT81 and IFT74. These regions are not required for stability of the IFT-B1 complex (Bhogaraju et al. 2013; Taschner et al. 2014), but instead form a tubulin-binding module. The amino-terminal IFT81 region was crystallized and displays the fold of a calponin-homology $(\mathrm{CH})$ domain, known to recognize tubulin/MTs (Wei et al. 2007; Ciferri et al. 2008; Bhogaraju et al. 2013). Although the IFT81 CH-domain itself can bind to tubulin dimers, it does so with low affinity. In complex with the amino terminus of IFT74, however, this affinity is significantly increased (Bhogaraju et al. 2013). The current model is that the IFT81 $\mathrm{CH}$-domain recognizes tubulin using conserved surface-exposed basic residues, and the highly positively charged amino terminus of IFT74 locks the cargo to the complex by electrostatic interactions with the negatively charged carboxy-terminal tubulin tails (Ehooks) (see Janke and Bulinski 2011). IFT81 proteins with mutations in the $\mathrm{CH}$ domain move normally by IFT in T. brucei flagella, but are unable to rescue the ciliogenesis defect cause by siRNA-mediated depletion of IFT81 in human cells (Bhogaraju et al. 2013). In Chlamydomonas, the expression of an IFT74 version lacking the amino-terminal positively charged region required for high-affinity tubulin binding did not abolish ciliogenesis, but slowed down ciliogenesis (Brown et al. 2015). The same was shown to be true also for cells carrying mutations in the $\mathrm{CH}$-domain of IFT81, but when IFT81N and IFT74N were mutated in combination the cells were able to assemble only very short flagella (Kubo et al. 2016).

Several lines of evidence imply that IFT81/ 74 may not be the only tubulin-binding site in the IFT complex. First, mutations in C. elegans IFT81 and IFT74 do not disrupt formation of sensory cilia (Kobayashi et al. 2007). Second, Drosophila melanogaster does not contain homologs of these proteins (Cole and Snell 2009), but nevertheless assembles sensory cilia by IFT (e.g., Sarpal et al. 2003). Last, the presence of only one dedicated tubulin-binding site in the IFT complex is in theory not sufficient to explain the fast initial kinetics of ciliogenesis in Chlamydomonas after deflagellation (Bhogaraju et al. 2014). Interestingly, three other IFT proteins within the IFT-B2 complex (IFT57, IFT54, and IFT38) contain amino-terminal $\mathrm{CH}$ domains just like IFT81 (Taschner et al. 2012; Schou et al. 2013), but two of those (IFT57 and IFT38) are engaged in intra-IFT interactions with IFT172 and IFT80 and do not bind tubulin (see Fig. 2) (Taschner et al. 2016). Recent results indicate that the $\mathrm{CH}$ domain of IFT54 is able to bind to tubulin with a similar affinity as IFT81/74, and the crystal structure revealed important residues for this interaction (Taschner et al. 2016). Two separate tubulinbinding sites within the IFT complex would be sufficient to explain the flagellar regeneration kinetics in Chlamydomonas, and future experiments should provide further insights into the transport of this important IFT cargo.

Although it is tempting to speculate that the IFT81/74 amino-terminal module and the IFT54 $\mathrm{CH}$ domain function in the transport of soluble tubulin dimers as an IFT cargo, alternative/additional functions of these domains cannot be excluded at this moment. Interaction with polymerized MTs has been reported both for IFT81N/74N (Bhogaraju et al. 2013) and IFT54 (Ling and Goeddel 2000; Taschner et al. 2016); and although it seems counterproductive for a complex that moves processively along MT tracks to also bind to them, a transient MT 
interaction could be involved in the localization of IFT complexes to the basal body region or may represent an intermediate stage in IFT turnaround at the ciliary tip. Alternatively, the MT binding function of these proteins could be linked to a nonciliary role in modulating the overall stability of cellular microtubules, as recently described for IFT54/TRAF3IP1 in mammalian cells (Berbari et al. 2011; Bizet et al. 2015).

\section{ARCHITECTURE OF THE IFT-A COMPLEX}

Although the IFT-A complex contains significantly fewer proteins than the IFT-B counterpart, much less information is available on IFT-A architecture and the specific functions of IFT-A subunits. Bioinformatic analysis predicted that four of the six IFT-A proteins (IFT144, 140, 122, and 121) share domain organization with membrane coat proteins (with amino-terminal WD40 $\beta$-propellers and an $\alpha$ solenoid carboxy-terminal tail) (Taschner et al. 2012), suggesting that they evolved from a protocoatomer protein present in an early ancestral cell (Jékely and Arendt 2006; van Dam et al. 2013). A study using human cell lines showed that three of the IFT-A components (IFT144, IFT140, and IFT122) form a subcomplex independent of the remaining three subunits, and this subcomplex was termed IFT-A core $(\mathrm{Mu}-$ khopadhyay et al. 2010). Experimental evidence regarding how these proteins interact is still missing, but their structural similarity to members of the coat protein complex I (COPI) makes it tempting to speculate that they form a trimeric complex via their amino-terminal $\beta$ propellers (Faini et al. 2013). A subsequent study in Chlamydomonas using yeast two-hybrid and coexpression/pulldown assays confirmed the existence of this "core" complex and reported additional direct interactions within the core (IFT144/140, IFT140/122), between the remaining noncore subunits (IFT121/43, IFT139/121), as well as between the two subcomplexes (IFT122/121) (Behal et al. 2011). Our own efforts to express IFT-A proteins and to reconstitute this complex confirmed that IFT139, IFT121, and IFT43 form a stable complex and demonstrated that IFT121 interacts with both IFT43 and IFT139 (M Taschner and E Lorentzen, unpubl.).

Functions of IFT-A Proteins in IFT-A Complex Stability and Cargo Transport

As mentioned earlier, mutations in IFT-A components typically result in stumpy flagella that accumulate IFT-B proteins similarly to what is observed in mutants of retrograde IFT motor subunits. This has been observed in model systems such as $C$. reinhardtii (for example, see Piperno et al. 1998; Iomini et al. 2009), C. elegans (for example, see Blacque et al. 2006; Efimenko et al. 2006), T. thermophila (Tsao and Gorovsky 2008b), D. melanogaster (Lee et al. 2008), and mouse (for example, see Tran et al. 2008; Cortellino et al. 2009; Liem et al. 2012). As described for the IFT-B complex, the similar mutant phenotypes of IFT-A mutants may be a result of IFT-A (sub)complex disruption. Mutation of IFT121 in Chlamydomonas destabilizes the other "noncore" IFT-A protein IFT139, leaving the core unaffected (Behal et al. 2011), similar to what was observed in mammalian cells (Mukhopadhyay et al. 2010). In an ift122 mutant (with a mutation in an IFT-A core component), the other two core members were unaffected, but the noncore proteins IFT139 and IFT121 were depleted (Behal et al. 2011). It thus seems that the noncore proteins are more dependent on the core proteins rather than the other way around. Some analyses also suggested that although the IFT-A core can move to the ciliary tip independently of the other subunits the return of this core to the base of the cilium depends on IFT139, 121, and 43 (Mukhopadhyay et al. 2010; Bredrup et al. 2011).

Most stumpy cilia observed in IFT-A mutant mice are associated with ectopic, ligandindependent activation of the Hh pathway (for example, see Tran et al. 2008; Qin et al. 2011; Liem et al. 2012), in strong contrast to IFT-B mutants, which typically display defects in pathway activation ( for examples, see Huangfu et al. 2003; Rix et al. 2011; Keady et al. 2012; Eguether et al. 2014; Swiderski et al. 2014). Interestingly, a mutant in the retrograde motor displayed similar short and bulgy cilia, but was deficient in $\mathrm{Hh}$ 
signaling (Ocbina et al. 2011), showing that the overactivation of the pathway cannot be explained solely by a defect in retrograde IFT. Indeed, the IFT-A core complex was shown to be important for the ciliary import of the protein TULP3 (Mukhopadhyay et al. 2010), a member of the Tubby protein family (Mukhopadhyay and Jackson 2011), which in turn mediates ciliary import of G-protein-coupled receptors (GPCRs), among which is the negative Hh regulator Gpr161 (Mukhopadhyay et al. 2013). Detailed information about which of the three IFT-A core proteins mediates the recognition of TULP3 is currently unavailable.

An example of a confirmed direct interaction between a specific IFT-A protein and a cargo came from studies involving the BBSome. IFT144 was shown to directly interact with BBS1 in mammalian cells, and hypomorphic mutations in C. elegans in IFT144/DYF-2 or in BBS1 that disrupt this interaction lead to exclusion of the BBSome from cilia and a defective return of IFT-B proteins from the ciliary tip (Wei et al. 2012). This was another example of the requirement of the IFT-A complex for ciliary cargo (i.e., the BBSome) import and provided important clues on the function of the BBSome in regulation of IFT particle assembly at the ciliary base and tip (see below).

\section{ASSOCIATION BETWEEN IFT-A AND IFT-B COMPLEXES AND THE FORMATION OF IFT TRAINS}

No specific direct interactions between IFT-A and IFT-B proteins have so far been demonstrated, and biochemical evidence suggests that such an interaction, if it occurs, is weak compared to intra-IFT-B and intra-IFT-A interactions. The initial characterization of the IFT complex showed that, although IFT-A and IFT$\mathrm{B}$ cosedimented in sucrose density gradients at low ionic strength, a slight increase in $\mathrm{NaCl}$ concentration led to their dissociation (Cole et al. 1998). Coimmunoprecipitation attempts between subunits of the two complexes led to contradictory results. Although some studies were unable to detect coprecipiation of IFT-A and IFT-B subunits (for example, see Cole et al.
1998; Baker et al. 2003; Follit et al. 2009; Lechtreck et al. 2009b; Fan et al. 2010), other studies did detect an interaction (Qin et al. 2004; Pedersen et al. 2005), although coprecipitation seemed to be dependent on the antibodies and pulldown conditions used. High-throughput pulldowns and mass-spectrometry analysis did not detect direct interactions between IFT-A and IFT-B (Boldt et al. 2016), but a recent study using Chlamydomonas provided evidence that the amino-terminal part of the IFT-B1 component IFT74 could be linking IFT-B and IFT-A. In a mutant strain missing this IFT74 region, the IFT-A complex was unable to enter the flagellum, and IFT-B components accumulated at a tip as a result (Brown et al. 2015).

As mentioned earlier, anterograde IFT in C. elegans uses two separate kinesin motors, namely, the slow heterotrimeric and faster homodimeric kinesin II (OSM-3) (Snow et al. 2004; Prevo et al. 2015). Another study showed that in BBS mutant worms ( $b b s-7$ and $b b s-8)$ the IFT-A complex moves at the slow speed of heterotrimeric kinesin II, whereas IFT-B is faster and seems to be transported by OSM-3. The authors concluded that instead of being tightly bound to each other IFT-A and B are physically held together by the BBSome (Ou et al. 2005a). Such a model would, however, not work for Chlamydomonas, in which the BBSome was shown to be substoichiometric to the IFT proteins (Lechtreck et al. 2009a). More information about the exact role of the BBSome in IFT complex formation was obtained later, again in work carried out in the nematode model. Hypomorphic mutations in BBS-1 and IFT144/DYF2 allow the BBSome to assemble IFT-A and -B complexes at the ciliary base and anterograde IFT-trains are properly formed, but the BBSome is no longer transported to the tip as an IFT cargo. According to the author's model, after disassembly of trains at the tip, the BBSome is not available to attach IFT-B particles to retrograde trains, leading to their accumulation at this location (Wei et al. 2012). In the bbs-7 and $b b s-8$ mutants used in the previous study (Ou et al. 2005a), BBSome function is also disrupted at the ciliary base, leading to dissociation of IFT-A and IFT-B already in the anterograde 
direction. Taken together, the data suggest that the BBSome mediates IFT-A and -B assembly at the base and tip of $C$. elegans sensory cilia.

In the early seminal studies of IFT in Chlamydomonas, IFT material was observed to oligomerize into long (several 100-nm) electron-dense IFT trains (also known as IFT rafts) (Kozminski et al. 1993, 1995). The most detailed view of IFT trains was published in an electrontomography study in plastic-embedded Chlamydomonas flagella (Pigino et al. 2009). A structural building block (most likely corresponding to the IFT complex and associated cargos) was seen to form a dimer that repeated every $40 \mathrm{~nm}$ along the longitudinal axis of the flagellum, implying that the IFT complexes not only make longitudinal but also lateral contacts (Pigino et al. 2009). While it was initially speculated that these long assemblies represented IFT trains moving in the anterograde direction (Pigino et al. 2009), it now became clear that they, in fact, are stalled trains, and that both anterograde and retrograde trains are significantly shorter and display a different periodicity (Stepanek and Pigino 2016; Vannuccini et al. 2016). The molecular basis of IFT train formation is still not understood, and it is not clear whether the IFT complex itself is able to form trains or whether association with motors, cargos, or other accessory factors is required. Regardless of the exact mechanism of IFT train formation, it appears to be a highly regulated process as the length of IFT trains is adjusted according to flagellar length in Chlamydomonas (Engel et al. 2009b). It is currently not known whether IFT train formation is evolutionarily conserved in all ciliated organisms and is a requirement for ciliogenesis.

\section{ASSOCIATION BETWEEN IFT COMPLEXES AND IFT MOTORS}

Several regulated interactions between the IFT complexes and the motors are necessary to ensure proper cycling of IFT trains between the ciliary base and tip. Kinesin II motor(s) power(s) anterograde movement of complexes carrying inactive dynein 2 as a cargo. After reaching the tip, kinesin inactivation and dynein activa- tion are a prerequisite for retrograde IFT. Interaction studies between IFT complex proteins and motors have so far not been very conclusive and, in some cases, contradictory (Baker et al. 2003; Qin et al. 2004; Follit et al. 2009; Liang et al. 2014). A direct interaction between heterotrimeric kinesin II and IFT20 was proposed for the mouse proteins based on a yeast two-hybrid assay (Baker et al. 2003), but this could not be confirmed in an independent study (Follit et al. 2009), and might have been a false positive interaction caused by coexpression of two coiled-coil proteins in the absence of their native binding partners. However, the IFT-B mutant phenotypes, often observed to have a general assembly defect, make it very likely that IFT$\mathrm{B}$ attaches to the kinesin motor for anterograde transport. This notion was confirmed by studies in Chlamydomonas (Liang et al. 2014) and mouse (Baker et al. 2003), which found specific coimmunoprecipiations between IFT-B and heterotrimeric kinesin II. In the green alga, a specific phosphorylation event on FLA8 (kinesin II motor subunit, a homolog of Kif3b) was shown to disrupt the interaction between the motor and IFT-B and thus to be important for IFT regulation (Liang et al. 2014). At the ciliary tip, this phosphorylation leads to dissociation and inactivation of the anterograde motor, and inhibition of phosphorylation results in IFT complex accumulation at the tip (Liang et al. 2014). After dissociation, the kinesin motor is able to exit the Chlamydomonas flagellum independently of retrograde transport (Pedersen et al. 2006; Engel et al. 2012), indicating that it returns to the ciliary base via diffusion. This is in contrast to the retrograde dynein motor that needs heterotrimeric kinesin II for transport to the tip, and so it is a bona fide anterograde IFT cargo attached to IFT-B potentially via IFT172 (Pedersen et al. 2006; Williamson et al. 2011). Retrograde IFT seems to depend on docking of the dynein complex to IFT-A (Williamson et al. 2011), consistent with the similar flagellar phenotypes of IFT-A and dynein mutants (Pazour et al. 1998; Piperno et al. 1998; Porter et al. 1999; Perrone et al. 2003; Iomini et al. 2009).

Apart from the fact that anterograde IFT relies on two distinct kinesin motors in 
The Intraflagellar Transport Machinery

C. elegans (Snow et al. 2004), another difference in this model system is the apparent attachment of heterotrimeric kinesin II to IFT-A instead of IFT-B (Ou et al. 2005a). Recently, a study showed that the heterotrimeric kinesin motor has an important function in importing IFT trains past the transition zone and into the ciliary compartment proper, after which the trains are "handed over" along the proximal segment to the faster homodimeric OSM-3 motor that transports them along the distal segment to the ciliary tip (Prevo et al. 2015). In contrast to the situation in Chlamydomonas, both kinesin motors in the nematode are retrograde IFT cargos (Prevo et al. 2015). Regarding direct attachment points between motors and cargos, it was found that Dyf-1 in C. elegans (the worm homolog of the IFT-B1 protein IFT70) is necessary for binding and/or activation of the OSM-3 motor, because in $d y f-1$ mutants the IFT trains are moved only by heterotrimeric kinesin II, and the OSM3 dependent distal singlet segment fails to form (Ou et al. 2005a). A direct interaction between the homologous proteins in mammals was suggested (Howard et al. 2013).

\section{CONCLUDING REMARKS}

Since the discovery of intraflagellar transport more than two decades ago, our understanding of this process has improved considerably. The identities of the main components of the IFT machinery are known, the architectures of these complexes are emerging, and our knowledge of cargo binding and IFT regulation is increasing. Nevertheless, much remains to be deciphered before we fully comprehend this transport mechanism. How do the 22 IFT proteins come together to form a multisubunit IFT complex in three dimensions? How do IFT complexes oligomerize into long IFT trains? What are the specific roles of the individual IFT subunits in cargo transport? How is cargo loading onto IFT trains regulated? What is the exact mechanism of motor attachment/activation, and how are these steps regulated to ensure unperturbed bidirectional IFT movement? A multidisciplinary approach to the study of IFT should provide answers to these questions.

\section{ACKNOWLEDGMENTS}

We apologize to our colleagues whose work could not be mentioned in this review because of space limitations. We thank the members of the Lorentzen laboratory for critical reading of the manuscript.

\section{REFERENCES}

Adams GM, Huang B, Luck DJ. 1982. Temperature-sensitive, assembly-defective flagella mutants of Chlamydomonas reinhardtii. Genetics 100: 579-586.

Adhiambo C, Blisnick T, Toutirais G, Delannoy E, Bastin P. 2009. A novel function for the atypical small $G$ protein Rab-like 5 in the assembly of the trypanosome flagellum. J Cell Sci 122: 834-841.

Ahmed NT, Gao C, Lucker BF, Cole DG, Mitchell DR. 2008. ODA16 aids axonemal outer row dynein assembly through an interaction with the intraflagellar transport machinery. J Cell Biol 183: 313-322.

Aldahmesh MA, Li Y, Alhashem A, Anazi S, Alkuraya H, Hashem M, Awaji AA, Sogaty S, Alkharashi A, Alzahrani S, et al. 2014. IFT27, encoding a small GTPase component of IFT particles, is mutated in a consanguineous family with Bardet-Biedl syndrome. Hum Mol Genet 23: 3307-3315.

Baker SA, Freeman K, Luby-Phelps K, Pazour GJ, Besharse JC. 2003. IFT20 links kinesin II with a mammalian intraflagellar transport complex that is conserved in motile flagella and sensory cilia. J Biol Chem 278: 3421134218.

Behal RH, Miller MS, Qin H, Lucker B, Jones A, Cole DG. 2011. Subunit interactions and organization of the Chlamydomonas reinhardtii intraflagellar transport complex A. J Biol Chem 287: 11689-11703.

Berbari NF, Kin NW, Sharma N, Michaud EJ, Kesterson RA, Yoder BK. 2011. Mutations in Traf3ip1 reveal defects in ciliogenesis, embryonic development, and altered cell size regulation. Dev Biol 360: 66-76.

Bhogaraju S, Taschner M, Morawetz M, Basquin C, Lorentzen E. 2011. Crystal structure of the intraflagellar transport complex 25/27. EMBO J 30: 1907-1918.

Bhogaraju S, Cajanek L, Fort C, Blisnick T, Weber K, Taschner M, Mizuno N, Lamla S, Bastin P, Nigg EA, et al. 2013. Molecular basis of tubulin transport within the cilium by IFT74 and IFT81. Science 341: 1009-1012.

Bhogaraju S, Weber K, Engel BD, Lechtreck KF, Lorentzen E. 2014. Getting tubulin to the tip of the cilium: One IFT train, many different tubulin cargo-binding sites? Bioessays 36: $463-467$.

Bizet AA, Becker-Heck A, Ryan R, Weber K, Filhol E, Krug P, Halbritter J, Delous M, Lasbennes MC, Linghu B, et al. 2015. Mutations in TRAF3IP1/IFT54 reveal a new role for IFT proteins in microtubule stabilization. Nat Commun 6: 8666.

Blacque OE, Leroux MR. 2006. Bardet-Biedl syndrome: An emerging pathomechanism of intracellular transport. Cell Mol Life Sci 63: 2145-2161. 
Blacque OE, Li C, Inglis PN, Esmail MA, Ou G, Mah AK, Baillie DL, Scholey JM, Leroux MR. 2006. The WD repeat-containing protein IFTA- 1 is required for retrograde intraflagellar transport. Mol Biol Cell 17: 5053-5062.

Boldt K, van Reeuwijk J, Lu Q, Koutroumpas K, Nguyen TM, Texier Y, van Beersum SE, Horn N, Willer JR, Mans DA, et al. 2016. An organelle-specific protein landscape identifies novel diseases and molecular mechanisms. Nat Commun 7: 11491.

Brazelton WJ, Amundsen CD, Silflow CD, Lefebvre PA. 2001. The bld1 mutation identifies the Chlamydomonas osm-6 homolog as a gene required for flagellar assembly. Curr Biol 11: 1591-1594.

Bredrup C, Saunier S, Oud MM, Fiskerstrand T, Hoischen A, Brackman D, Leh SM, Midtbø M, Filhol E, Bole-Feysot C, et al. 2011. Ciliopathies with skeletal anomalies and renal insufficiency due to mutations in the IFT-A gene WDR19. Am J Hum Genet 89: 634-643.

Brown JM, Cochran DA, Craige B, Kubo T, Witman GB. 2015. Assembly of IFT trains at the ciliary base depends on IFT74. Curr Biol 25: 1583-1593.

Bryan JH. 1983. Abnormal cilia in a male-sterile mutant mouse. Virchows Arch A Pathol Anat Histopathol 400: 77-86.

Ciferri C, Pasqualato S, Screpanti E, Varetti G, Santaguida S, Reis Dos G, Maiolica A, Polka J, De Luca JG, De Wulf P, et al. 2008. Implications for kinetochore-microtubule attachment from the structure of an engineered Ndc80 complex. Cell 133: 427-439.

Cole DG, Snell WJ. 2009. SnapShot: Intraflagellar transport. Cell 137: 784-784.e1.

Cole DG, Chinn SW, Wedaman KP, Hall K, Vuong T, Scholey JM. 1993. Novel heterotrimeric kinesin-related protein purified from sea urchin eggs. Nature 366: 268-270.

Cole DG, Diener DR, Himelblau AL, Beech PL, Fuster JC, Rosenbaum JL. 1998. Chlamydomonas kinesin-II-dependent intraflagellar transport (IFT): IFT particles contain proteins required for ciliary assembly in Caenorhabditis elegans sensory neurons. J Cell Biol 141: 993-1008.

Cortellino S, Wang C, Wang B, Bassi MR, Caretti E, Champeval D, Calmont A, Jarnik M, Burch J, Zaret KS, et al. 2009. Defective ciliogenesis, embryonic lethality and severe impairment of the Sonic Hedgehog pathway caused by inactivation of the mouse complex A intraflagellar transport gene Ift122/Wdr10, partially overlapping with the DNA repair gene Med1/Mbd4. Dev Biol 325: 225237.

Craft JM, Harris JA, Hyman S, Kner P, Lechtreck KF. 2015. Tubulin transport by IFT is upregulated during ciliary growth by a cilium-autonomous mechanism. J Cell Biol 208: $223-237$.

Dave D, Wloga D, Gaertig J. 2009. Manipulating ciliary protein-encoding genes in Tetrahymena thermophila. Methods Cell Biol 93: 1-20.

Deane JA, Cole DG, Seeley ES, Diener DR, Rosenbaum JL. 2001. Localization of intraflagellar transport protein IFT52 identifies basal body transitional fibers as the docking site for IFT particles. Curr Biol 11: 1586-1590.

Efimenko E, Blacque OE, Ou G, Haycraft CJ, Yoder BK, Scholey JM, Leroux MR, Swoboda P. 2006. Caenorhabditis elegans DYF-2, an orthologue of human WDR19, is a component of the intraflagellar transport machinery in sensory cilia. Mol Biol Cell 17: 4801-4811.

Eguether T, San Agustin JT, Keady BT, Jonassen JA, Liang Y, Francis R, Tobita K, Johnson CA, Abdelhamed ZA, Lo CW, et al. 2014. IFT27 links the BBSome to IFT for maintenance of the ciliary signaling compartment. Dev Cell 31: $279-290$.

Engel BD, Lechtreck KF, Sakai T, Ikebe M, Witman GB, Marshall WF. 2009a. Total internal reflection fluorescence (TIRF) microscopy of Chlamydomonas flagella. Methods Cell Biol 93: 157-177.

Engel BD, Ludington WB, Marshall WF. 2009b. Intraflagellar transport particle size scales inversely with flagellar length: Revisiting the balance-point length control model. J Cell Biol 187: 81-89.

Engel BD, Ishikawa H, Wemmer KA, Geimer S, Wakabayashi KI, Hirono M, Craige B, Pazour GJ, Witman GB, Kamiya $\mathrm{R}$, et al. 2012. The role of retrograde intraflagellar transport in flagellar assembly, maintenance, and function. $J$ Cell Biol 199: 151-167.

Faini M, Beck R, Wieland FT, Briggs JAG. 2013. Vesicle coats: Structure, function, and general principles of assembly. Trends Cell Biol 23: 279-288.

Fan ZC, Behal RH, Geimer S, Wang Z, Williamson SM, Zhang H, Cole DG, Qin H. 2010. Chlamydomonas IFT70/CrDYF-1 is a core component of IFT particle complex B and is required for flagellar assembly. $\mathrm{Mol}$ Biol Cell 21: 2696-2706.

Fliegauf M, Benzing T, Omran H. 2007. When cilia go bad: Cilia defects and ciliopathies. Nat Rev Mol Cell Biol 8: 880-893.

Follit JA, Tuft RA, Fogarty KE, Pazour GJ. 2006. The intraflagellar transport protein IFT20 is associated with the Golgi complex and is required for cilia assembly. Mol Biol Cell 17: 3781-3792.

Follit JA, San Agustin JT, Xu F, Jonassen JA, Samtani R, Lo CW, Pazour GJ. 2008. The Golgin GMAP210/TRIP11 anchors IFT20 to the Golgi complex. PLoS Genet 4: e1000315.

Follit JA, Xu F, Keady BT, Pazour GJ. 2009. Characterization of mouse IFT complex B. Cell Motil Cytoskeleton 66: 457468.

Hao L, Acar S, Evans J, Ou G, Scholey JM. 2009. Analysis of intraflagellar transport in C. elegans sensory cilia. Methods Cell Biol 93: 235-266.

Hao L, Thein M, Brust-Mascher I, Civelekoglu-Scholey G, Lu Y, Acar S, Prevo B, Shaham S, Scholey JM. 2011. Intraflagellar transport delivers tubulin isotypes to sensory cilium middle and distal segments. Nat Cell Biol 13: 790-798.

Harris JA, Liu Y, Yang P, Kner P, Lechtreck KF. 2016. Singleparticle imaging reveals intraflagellar transport-independent transport and accumulation of EB1 in Chlamydomonas flagella. Mol Biol Cell 27: 295-307.

Hou Y, Pazour GJ, Witman GB. 2004. A dynein light intermediate chain, D1bLIC, is required for retrograde intraflagellar transport. Mol Biol Cell 15: 4382-4394.

Hou Y, Qin H, Follit JA, Pazour GJ, Rosenbaum JL, Witman GB. 2007. Functional analysis of an individual IFT protein: IFT46 is required for transport of outer dynein arms into flagella. J Cell Biol 176: 653-665. 
Howard PW, Jue SF, Maurer RA. 2013. Interaction of mouse TTC30/DYF-1 with multiple intraflagellar transport complex B proteins and KIF17. Exp Cell Res 319: 22752281.

Huang B, Rifkin MR, Luck DJ. 1977. Temperature-sensitive mutations affecting flagellar assembly and function in Chlamydomonas reinhardtii. J Cell Biol 72: 67-85.

Huangfu D, Liu A, Rakeman AS, Murcia NS, Niswander L, Anderson KV. 2003. Hedgehog signalling in the mouse requires intraflagellar transport proteins. Nature 426: $83-87$.

Huet D, Blisnick T, Perrot S, Bastin P. 2014. The GTPase IFT27 is involved in both anterograde and retrograde intraflagellar transport. eLife 3: e02419.

Inglis PN, Ou G, Leroux MR, Scholey JM. 2007. The sensory cilia of Caenorhabditis elegans. WormBook doi: 10.1895/ wormbook.1.126.2.

Insinna C, Humby M, Sedmak T, Wolfrum U, Besharse JC. 2009. Different roles for KIF17 and kinesin II in photoreceptor development and maintenance. Dev Dyn 238: 2211-2222.

Iomini C, Babaev-Khaimov V, Sassaroli M, Piperno G. 2001. Protein particles in Chlamydomonas flagella undergo a transport cycle consisting of four phases. J Cell Biol 153: $13-24$.

Iomini C, Li L, Esparza JM, Dutcher SK. 2009. Retrograde intraflagellar transport mutants identify complex A proteins with multiple genetic interactions in Chlamydomonas reinhardtii. Genetics 183: 885-896.

Ishikawa H, Marshall WF. 2015. Efficient live fluorescence imaging of intraflagellar transport in mammalian primary cilia. Methods Cell Biol 127: 189-201.

Ishikawa $\mathrm{H}$, Ide $\mathrm{T}$, Yagi $\mathrm{T}$, Jiang $\mathrm{X}$, Hirono $\mathrm{M}$, Sasaki $\mathrm{H}$, Yanagisawa H, Wemmer KA, Stainier DY, Qin H, et al. 2014. TTC26/DYF13 is an intraflagellar transport protein required for transport of motility-related proteins into flagella. eLife 3: e01566.

Janke C, Bulinski JC. 2011. Post-translational regulation of the microtubule cytoskeleton: Mechanisms and functions. Nat Rev Mol Cell Biol 12: 773-786.

Jékely G, Arendt D. 2006. Evolution of intraflagellar transport from coated vesicles and autogenous origin of the eukaryotic cilium. Bioessays 28: 191-198.

Jiang YY, Lechtreck K, Gaertig J. 2015. Total internal reflection fluorescence microscopy of intraflagellar transport in Tetrahymena thermophila. Methods Cell Biol 127: 445456.

Jin H, White SR, Shida T, Schulz S, Aguiar M, Gygi SP, Bazan JF, Nachury MV. 2010. The conserved Bardet-Biedl syndrome proteins assemble a coat that traffics membrane proteins to cilia. Cell 141: 1208-1219.

Johnson KA, Rosenbaum JL. 1992. Polarity of flagellar assembly in Chlamydomonas. J Cell Biol 119: 1605-1611.

Jonassen JA, San Agustin J, Follit JA, Pazour GJ. 2008. Deletion of IFT20 in the mouse kidney causes misorientation of the mitotic spindle and cystic kidney disease. J Cell Biol 183: $377-384$

Katoh Y, Terada M, Nishijima Y, Takei R, Nozaki S, Hamada H, Nakayama K. 2016. Overall architecture of the intraflagellar transport (IFT)-B complex containing Cluap1/
IFT38 as an essential component of the IFT-B peripheral subcomplex. J Biol Chem 291: 10962-10975.

Keady BT, Samtani R, Tobita K, Tsuchya M, San Agustin JT, Follit JA, Jonassen JA, Subramanian R, Lo CW, Pazour GJ. 2012. IFT25 links the signal-dependent movement of Hedgehog components to intraflagellar transport. Dev Cell 22: 940-951.

Kobayashi T, Gengyo-Ando K, Ishihara T, Katsura I, Mitani S. 2007. IFT-81 and IFT-74 are required for intraflagellar transport in C. elegans. Genes Cells 12: 593-602.

Kozminski KG, Johnson KA, Forscher P, Rosenbaum JL. 1993. A motility in the eukaryotic flagellum unrelated to flagellar beating. Proc Natl Acad Sci 90: 5519-5523.

Kozminski KG, Beech PL, Rosenbaum JL. 1995. The Chlamydomonas kinesin-like protein FLA10 is involved in motility associated with the flagellar membrane. J Cell Biol 131: 1517-1527.

Kubo T, Brown JM, Bellve K, Craige B, Craft JM, Fogarty K, Lechtreck KF, Witman GB. 2016. The IFT81 and IFT74 $\mathrm{N}$-termini together form the major module for intraflagellar transport of tubulin. J Cell Sci doi: 10.1242/ jcs. 187120

Kunitomo H, Iino Y. 2008. Caenorhabditis elegans DYF-11, an orthologue of mammalian Traf3ip1/MIP-T3, is required for sensory cilia formation. Genes Cells 13: 13-25.

Lechtreck KF, Johnson EC, Sakai T, Cochran D, Ballif BA, Rush J, Pazour GJ, Ikebe M, Witman GB. 2009a. The Chlamydomonas reinhardtii BBSome is an IFT cargo required for export of specific signaling proteins from flagella. J Cell Biol 187: 1117-1132.

Lechtreck KF, Luro S, Awata J, Witman GB. 2009b. HA-tagging of putative flagellar proteins in Chlamydomonas reinhardtii identifies a novel protein of intraflagellar transport complex B. Cell Motil Cytoskeleton 66: 469-482.

Lee E, Sivan-Loukianova E, Eberl DF, Kernan MJ. 2008. An IFT-A protein is required to delimit functionally distinct zones in mechanosensory cilia. Curr Biol 18: 1899-1906.

Lee MS, Hwang KS, Oh HW, Ji-Ae K, Kim HT, Cho HS, Lee JJ, Yeong Ko J, Choi JH, Jeong YM, et al. 2015. IFT46 plays an essential role in cilia development. Dev Biol 400: 248 257.

Liang Y, Pang Y, Wu Q, Hu Z, Han X, Xu Y, Deng H, Pan J. 2014. FLA8/KIF3B phosphorylation regulates kinesin-II interaction with IFT-B to control IFT entry and turnaround. Dev Cell 30: 585-597.

Liem KF, Ashe A, He M, Satir P, Moran J, Beier D, Wicking C, Anderson KV. 2012. The IFT-A complex regulates Shh signaling through cilia structure and membrane protein trafficking. J Cell Biol 197: 789-800.

Liew GM, Ye F, Nager AR, Murphy JP, Lee JS, Aguiar M, Breslow DK, Gygi SP, Nachury MV. 2014. The intraflagellar transport protein IFT27 promotes BBSome exit from cilia through the GTPase ARL6/BBS3. Dev Cell 31: 265278.

Lindemann CB, Lesich KA. 2010. Flagellar and ciliary beating: The proven and the possible. J Cell Sci 123: 519-528.

Ling L, Goeddel DV. 2000. MIP-T3, a novel protein linking tumor necrosis factor receptor-associated factor 3 to the microtubule network. J Biol Chem 275: 23852-23860.

Liu Q, Tan G, Levenkova N, Li T, Pugh EN, Rux JJ, Speicher DW, Pierce EA. 2007. The proteome of the mouse pho- 
toreceptor sensory cilium complex. Mol Cell Proteomics 6: $1299-1317$.

Loktev AV, Zhang Q, Beck JS, Searby CC, Scheetz TE, Bazan JF, Slusarski DC, Sheffield VC, Jackson PK, Nachury MV. 2008. A BBSome subunit links ciliogenesis, microtubule stability, and acetylation. Dev Cell 15: 854-865.

Lucker BF, Behal RH, Qin H, Siron LC, Taggart WD, Rosenbaum JL, Cole DG. 2005. Characterization of the intraflagellar transport complex B core: Direct interaction of the IFT81 and IFT74/72 subunits. J Biol Chem 280: 27688-27696.

Lucker BF, Miller MS, Dziedzic SA, Blackmarr PT, Cole DG. 2010. Direct interactions of intraflagellar transport complex B proteins IFT88, IFT52, and IFT46. J Biol Chem 285: $21508-21518$.

Marszalek JR, Ruiz-Lozano P, Roberts E, Chien KR, Goldstein LS. 1999. Situs inversus and embryonic ciliary morphogenesis defects in mouse mutants lacking the KIF3A subunit of kinesin-II. Proc Natl Acad Sci 96: 5043-5048.

May SR, Ashique AM, Karlen M, Wang B, Shen Y, Zarbalis K, Reiter J, Ericson J, Peterson AS. 2005. Loss of the retrograde motor for IFT disrupts localization of Smo to cilia and prevents the expression of both activator and repressor functions of Gli. Dev Biol 287: 378-389.

Mick DU, Rodrigues RB, Leib RD, Adams CM, Chien AS, Gygi SP, Nachury MV. 2015. Proteomics of primary cilia by proximity labeling. Dev Cell 35: 497-512.

Mourão A, Nager AR, Nachury MV, Lorentzen E. 2014. Structural basis for membrane targeting of the BBSome by ARL6. Nat Struct Mol Biol 21: 1035-1041.

Mukhopadhyay S, Jackson PK. 2011. The tubby family proteins. Genome Biol 12: 225.

Mukhopadhyay S, Wen X, Chih B, Nelson CD, Lane WS, Scales SJ, Jackson PK. 2010. TULP3 bridges the IFT-A complex and membrane phosphoinositides to promote trafficking of $\mathrm{G}$ protein-coupled receptors into primary cilia. Genes Dev 24: 2180-2193.

Mukhopadhyay S, Wen X, Ratti N, Loktev A, Rangell L, Scales SJ, Jackson PK. 2013. The ciliary G-protein-coupled receptor Gpr161 negatively regulates the Sonic Hedgehog pathway via cAMP signaling. Cell 152: 210-223.

Nonaka S, Tanaka Y, Okada Y, Takeda S, Harada A, Kanai Y, Kido M, Hirokawa N. 1998. Randomization of left-right asymmetry due to loss of nodal cilia generating leftward flow of extraembryonic fluid in mice lacking KIF3B motor protein. Cell 95: 829-837.

Ocbina PJR, Eggenschwiler JT, Moskowitz I, Anderson KV. 2011. Complex interactions between genes controlling trafficking in primary cilia. Nat Genet 43: 547-553.

Omori Y, Zhao C, Saras A, Mukhopadhyay S, Kim W, Furukawa T, Sengupta P, Veraksa A, Malicki J. 2008. Elipsa is an early determinant of ciliogenesis that links the IFT particle to membrane-associated small GTPase Rab8. Nat Cell Biol 10: 437-444.

Ostrowski LE, Blackburn K, Radde KM, Moyer MB, Schlatzer DM, Moseley A, Boucher RC. 2002. A proteomic analysis of human cilia: Identification of novel components. Mol Cell Proteomics 1: 451-465.

Ou G, Blacque OE, Snow JJ, Leroux MR, Scholey JM. 2005a. Functional coordination of intraflagellar transport motors. Nature 436: 583-587.
Ou G, Qin H, Rosenbaum JL, Scholey JM. 2005b. The PKD protein qilin undergoes intraflagellar transport. Curr Biol 15: R410-R411.

Pasek RC, Berbari NF, Lewis WR, Kesterson RA, Yoder BK. 2012. Mammalian Clusterin associated protein 1 is an evolutionarily conserved protein required for ciliogenesis. Cilia 1: 20

Pazour GJ, Wilkerson CG, Witman GB. 1998. A dynein light chain is essential for the retrograde particle movement of intraflagellar transport (IFT). J Cell Biol 141: 979-992.

Pazour GJ, Dickert BL, Vucica Y, Seeley ES, Rosenbaum JL, Witman GB, Cole DG. 2000. Chlamydomonas IFT88 and its mouse homologue, polycystic kidney disease gene $\operatorname{tg} 737$, are required for assembly of cilia and flagella. $J$ Cell Biol 151: 709-718.

Pazour GJ, Agrin N, Leszyk J, Witman GB. 2005. Proteomic analysis of a eukaryotic cilium. J Cell Biol 170: 103-113.

Pedersen LB, Geimer S, Sloboda RD, Rosenbaum JL. 2003. The microtubule plus end-tracking protein EB1 is localized to the flagellar tip and basal bodies in Chlamydomonas reinhardtii. Curr Biol 13: 1969-1974.

Pedersen LB, Miller MS, Geimer S, Leitch JM, Rosenbaum JL, Cole DG. 2005. Chlamydomonas IFT172 is encoded by FLA11, interacts with CrEB1, and regulates IFT at the flagellar tip. Curr Biol 15: 262-266.

Pedersen LB, Geimer S, Rosenbaum JL. 2006. Dissecting the molecular mechanisms of intraflagellar transport in Chlamydomonas. Curr Biol 16: 450-459.

Perrone CA, Tritschler D, Taulman P, Bower R, Yoder BK, Porter ME. 2003. A novel dynein light intermediate chain colocalizes with the retrograde motor for intraflagellar transport at sites of axoneme assembly in Chlamydomonas and mammalian cells. Mol Biol Cell 14: 2041-2056.

Pigino G, Geimer S, Lanzavecchia S, Paccagnini E, Cantele F, Diener DR, Rosenbaum JL, Lupetti P. 2009. Electron-tomographic analysis of intraflagellar transport particle trains in situ. J Cell Biol 187: 135-148.

Piperno G, Mead K. 1997. Transport of a novel complex in the cytoplasmic matrix of Chlamydomonas flagella. Proc Natl Acad Sci 94: 4457-4462.

Piperno G, Mead K, Henderson S. 1996. Inner dynein arms but not outer dynein arms require the activity of kinesin homologue protein KHP1(FLA10) to reach the distal part of flagella in Chlamydomonas. J Cell Biol 133: 371379.

Piperno G, Siuda E, Henderson S, Segil M, Vaananen H, Sassaroli M. 1998. Distinct mutants of retrograde intraflagellar transport (IFT) share similar morphological and molecular defects. J Cell Biol 143: 1591-1601.

Porter ME, Bower R, Knott JA, Byrd P, Dentler W. 1999. Cytoplasmic dynein heavy chain $1 \mathrm{~b}$ is required for flagellar assembly in Chlamydomonas. Mol Biol Cell 10: 693712.

Prevo B, Mangeol P, Oswald F, Scholey JM, Peterman EJG. 2015. Functional differentiation of cooperating kinesin-2 motors orchestrates cargo import and transport in C. elegans cilia. Nat Cell Biol 17: 1536-1545.

Qin H, Diener DR, Geimer S, Cole DG, Rosenbaum JL. 2004. Intraflagellar transport (IFT) cargo: IFT transports flagellar precursors to the tip and turnover products to the cell body. J Cell Biol 164: 255-266. 
Qin J, Lin Y, Norman RX, Ko HW, Eggenschwiler JT. 2011. Intraflagellar transport protein 122 antagonizes Sonic Hedgehog signaling and controls ciliary localization of pathway components. Proc Natl Acad Sci 108: 1456-1461.

Reiter JF, Blacque OE, Leroux MR. 2012. The base of the cilium: Roles for transition fibres and the transition zone in ciliary formation, maintenance and compartmentalization. EMBO Rep 13: 608-618.

Richey EA, Qin H. 2012. Dissecting the sequential assembly and localization of intraflagellar transport particle complex B in Chlamydomonas. PLoS ONE 7: e43118.

Rix S, Calmont A, Scambler PJ, Beales PL. 2011. An Ift80 mouse model of short rib polydactyly syndromes shows defects in hedgehog signalling without loss or malformation of cilia. Hum Mol Genet 20: 1306-1314.

Rosenbaum JL, Child FM. 1967. Flagellar regeneration in protozoan flagellates. J Cell Biol 34: 345-364.

Rosenbaum JL, Moulder JE, Ringo DL. 1969. Flagellar elongation and shortening in Chlamydomonas. The use of cycloheximide and colchicine to study the synthesis and assembly of flagellar proteins. J Cell Biol 41: 600-619.

Santi-Rocca J, Chenouard N, Fort C, Lagache T, Olivo-Marin JC, Bastin P. 2015. Imaging intraflagellar transport in trypanosomes. Methods Cell Biol 127: 487-508.

Sarpal R, Todi SV, Sivan-Loukianova E, Shirolikar S, Subramanian N, Raff EC, Erickson JW, Ray K, Eberl DF. 2003. Drosophila KAP interacts with the kinesin II motor subunit KLP64D to assemble chordotonal sensory cilia, but not sperm tails. Curr Biol 13: 1687-1696.

Schou KB, Andersen JS, Pedersen LB. 2013. A divergent calponin homology (NN-CH) domain defines a novel family: Implications for evolution of ciliary IFT complex B proteins. Bioinformatics 30: 899-902.

Seo S, Zhang Q, Bugge K, Breslow DK, Searby CC, Nachury MV, Sheffield VC. 2011. A novel protein LZTFL1 regulates ciliary trafficking of the BBSome and Smoothened. PLoS Genet 7: e1002358.

Signor D, Wedaman KP, Orozco JT, Dwyer ND, Bargmann CI, Rose LS, Scholey JM. 1999. Role of a class DHC1b dynein in retrograde transport of IFT motors and IFT raft particles along cilia, but not dendrites, in chemosensory neurons of living Caenorhabditis elegans. J Cell Biol 147: 519-530.

Snow JJ, Ou G, Gunnarson AL, Walker MRS, Zhou HM, Brust-Mascher I, Scholey JM. 2004. Two anterograde intraflagellar transport motors cooperate to build sensory cilia on C. elegans neurons. Nat Cell Biol 6: 1109-1113.

Stepanek L, Pigino G. 2016. Microtubule doublets are double-track railways for intraflagellar transport trains. Science 352: 721-724

Swiderski RE, Nakano Y, Mullins RF, Seo S, Bánfi B. 2014. A mutation in the mouse $t t c 26$ gene leads to impaired hedgehog signaling. PLoS Genet 10: e1004689.

Taschner M, Bhogaraju S, Vetter M, Morawetz M, Lorentzen E. 2011. Biochemical mapping of interactions within the intraflagellar transport (IFT) B core complex: IFT52 binds directly to four other IFT-B subunits. J Biol Chem 286: $26344-26352$.

Taschner M, Bhogaraju S, Lorentzen E. 2012. Architecture and function of IFT complex proteins in ciliogenesis. Differentiation 83: S12-S22.
Taschner M, Kotsis F, Braeuer P, Kuehn EW, Lorentzen E. 2014. Crystal structures of IFT70/52 and IFT52/46 provide insight into intraflagellar transport B core complex assembly. J Cell Biol 207: 269-282.

Taschner M, Weber K, Mourão A, Vetter M, Awasthi M, Stiegler M, Bhogaraju S, Lorentzen E. 2016. Intraflagellar transport proteins $172,80,57,54,38$, and 20 form a stable tubulin-binding IFT-B2 complex. EMBO J 35: 773-790.

Tran PV, Haycraft CJ, Besschetnova TY, Turbe-Doan A, Stottmann RW, Herron BJ, Chesebro AL, Qiu H, Scherz PJ, Shah JV, et al. 2008. THM1 negatively modulates mouse sonic hedgehog signal transduction and affects retrograde intraflagellar transport in cilia. Nat Genet 40: 403-410.

Tsao CC, Gorovsky MA. 2008a. Different effects of Tetrahymena IFT172 domains on anterograde and retrograde intraflagellar transport. Mol Biol Cell 19: 1450-1461.

Tsao CC, Gorovsky MA. 2008b. Tetrahymena IFT122A is not essential for cilia assembly but plays a role in returning IFT proteins from the ciliary tip to the cell body. J Cell Sci 121: $428-436$.

van Dam TJP, Townsend MJ, Turk M, Schlessinger A, Sali A, Field MC, Huynen MA. 2013. Evolution of modular intraflagerllar transport from a coatomer-like progenitor. Proc Natl Acad Sci 110: 6943-6948.

Vannuccini E, Paccagnini E, Cantele F, Gentile M, Dini D, Fino F, Diener D, Mencarelli C, Lupetti P. 2016. Two classes of short intraflagellar transport trains with different 3D structures are present in Chlamydomonas flagella. J Cell Sci 129: 2064-2074.

Walther Z, Vashishtha M, Hall JL. 1994. The Chlamydomonas FLA10 gene encodes a novel kinesin-homologous protein. J Cell Biol 126: 175-188.

Wang Q, Pan J, Snell WJ. 2006. Intraflagellar transport particles participate directly in cilium-generated signaling in Chlamydomonas. Cell 125: 549-562.

Wang Z, Fan ZC, Williamson SM, Qin H. 2009. Intraflagellar transport (IFT) protein IFT25 is a phosphoprotein component of IFT complex B and physically interacts with IFT27 in Chlamydomonas. PLoS ONE 4: e5384.

Wei RR, Al-Bassam J, Harrison SC. 2007. The Ndc80/HEC1 complex is a contact point for kinetochore-microtubule attachment. Nat Struct Mol Biol 14: 54-59.

Wei Q, Zhang Y, Li Y, Zhang Q, Ling K, Hu J. 2012. The BBSome controls IFT assembly and turnaround in cilia. Nat Cell Biol 14: 950-957.

Williams CL, McIntyre JC, Norris SR, Jenkins PM, Zhang L, Pei Q, Verhey K, Martens JR. 2014. Direct evidence for BBSome-associated intraflagellar transport reveals distinct properties of native mammalian cilia. Nat Commun 5: 5813.

Williamson SM, Silva DA, Richey E, Qin H. 2011. Probing the role of IFT particle complex A and B in flagellar entry and exit of IFT-dynein in Chlamydomonas. Protoplasma 249: 851-856.

Zhao C, Malicki J. 2011. Nephrocystins and MKS proteins interact with IFT particle and facilitate transport of selected ciliary cargos. EMBO J 30: 2532-2544.

Zhao C, Omori Y, Brodowska K, Kovach P, Malicki J. 2012. Kinesin-2 family in vertebrate ciliogenesis. Proc Natl Acad Sci 109: 2388-2393. 


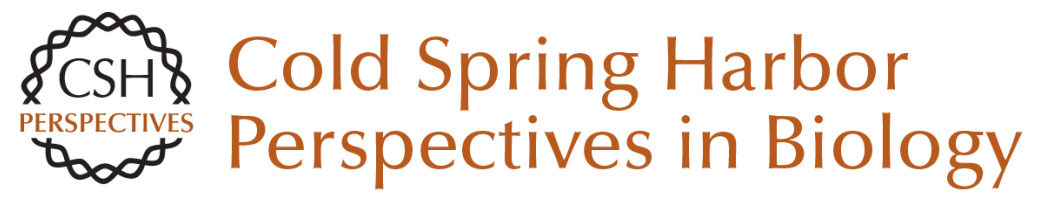

\section{The Intraflagellar Transport Machinery}

Michael Taschner and Esben Lorentzen

Cold Spring Harb Perspect Biol 2016; doi: 10.1101/cshperspect.a028092 originally published online June 28, 2016

\section{Subject Collection Cilia}

Ciliary Mechanisms of Cyst Formation in

Polycystic Kidney Disease

Ming Ma, Anna-Rachel Gallagher and Stefan Somlo

Photoreceptor Cilia and Retinal Ciliopathies Kinga M. Bujakowska, Qin Liu and Eric A. Pierce

G-Protein-Coupled Receptor Signaling in Cilia Kirk Mykytyn and Candice Askwith

Evolution of Cilia David R. Mitchell

Transition Zone Migration: A Mechanism for Cytoplasmic Ciliogenesis and Postaxonemal Centriole Elongation

Tomer Avidor-Reiss, Andrew Ha and Marcus L. Basiri

Cilia and Obesity

Christian Vaisse, Jeremy F. Reiter and Nicolas F. Berbari

Posttranslational Modifications of Tubulin and Cilia

Dorota Wloga, Ewa Joachimiak, Panagiota Louka, et al.
Cilia in Left-Right Symmetry Breaking Kyosuke Shinohara and Hiroshi Hamada

Discovery, Diagnosis, and Etiology of Craniofacial Ciliopathies Elizabeth N. Schock and Samantha A. Brugmann

Axoneme Structure from Motile Cilia Takashi Ishikawa

Cilia and Ciliopathies in Congenital Heart Disease Nikolai T. Klena, Brian C. Gibbs and Cecilia W. Lo

Sperm Sensory Signaling Dagmar Wachten, Jan F. Jikeli and U. Benjamin Kaupp

\section{Primary Cilia and Coordination of Receptor} Tyrosine Kinase (RTK) and Transforming Growth Factor $\beta$ (TGF- $\beta$ ) Signaling Søren T. Christensen, Stine K. Morthorst, Johanne B. Mogensen, et al.

Primary Cilia and Mammalian Hedgehog Signaling Fiona Bangs and Kathryn V. Anderson

For additional articles in this collection, see http://cshperspectives.cshlp.org/cgi/collection/

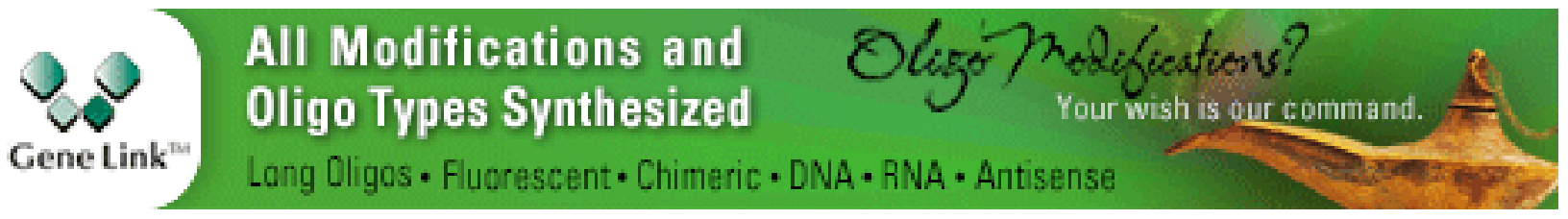


Radial Spokes--A Snapshot of the Motility Regulation, Assembly, and Evolution of Cilia and Flagella

Xiaoyan Zhu, Yi Liu and Pinfen Yang
Cilia and Mucociliary Clearance

Ximena M. Bustamante-Marin and Lawrence E. Ostrowski

For additional articles in this collection, see http://cshperspectives.cshlp.org/cgi/collection/

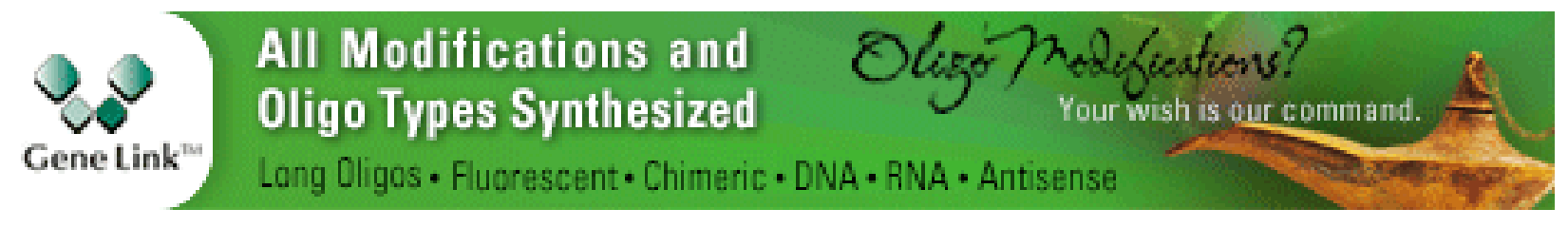

Copyright @ 2016 Cold Spring Harbor Laboratory Press; all rights reserved 